\title{
TINGKAT PENGETAHUAN PASIEN TENTANG SWAMEDIKASI OBAT
}

\author{
Hilda Suherman ${ }^{1)}$, Dina Febrina ${ }^{2)}$ \\ Program Studi Farmasi Sekolah Tinggi Ilmu Kesehatan Harapan Bangsa Purwokerto \\ ${ }^{1)}$ hildasuherman@shb.ac.id, ${ }^{2)}$ dinafebrina@shb.ac.id
}

\begin{abstract}
Abstrak
Swamedikasi adalah upaya manusia untuk mengobati penyakit atau gejala penyakit ringan seperti demam, batuk, flu, nyeri dan lain-lain tanpa resep dokter. Pada pelaksanaannya, keterbatasan pengetahuan akan obat dan penggunaannya dapat menjadi sumber kesalahan pengobatan (medication error). Penelitian ini dilakukan dengan metode penelitian deskriptif cross sectional. Data dikumpulkan melalui teknik pengisian kuesioner yang telah divalidasi. Sebanyak 300 orang responden yang terlibat dalam penelitian ini dipilih dengan metode consecutive sampling dari 3 apotek di Kota Purwokerto yang ditentukan secara proporsional sesuai dengan populasi masingmasing apotek. Data dianalisis dengan uji Chi-square dan uji Fisher menggunakan Statistical Product and Servicer Solution (SPSS) versi 17. Hasil penelitian menunjukkan bahwa tingkat pengetahuan pasien 22,6\% tergolong buruk, $48 \%$ tergolong sedang, dan 29,4\% tergolong baik. Penggunaan obat swamedikasi $26,3 \%$ tidak rasional dan $73,7 \%$ rasional. Berdasarkan hasil penelitian diperoleh bahwa tingkat pengetahuan pasien tergolong sedang dengan persentase $48 \%$. Sedangkan rasionalitas swamedikasi tergolong rasional dengan persentase $73,7 \%$.
\end{abstract}

Kata Kunci: Swamedikasi, Apotek, Pengetahuan, Rasionalitas penggunaan obat

\begin{abstract}
Self-medication is a human effort to treat diseases or symptoms of minor ailments such as fever, cough, flu, pain and others without a doctor's prescription. In practice, limited knowledge of drugs and their use can be a source of medication errors (medication error). This research was conducted with a cross sectional descriptive research method. Data was collected through a validated questionnaire filling technique. A total of 300 respondents involved in this study were selected by consecutive sampling method from 3 pharmacies in the city of Purwokerto which were determined proportionally according to the population of each pharmacy. Data were analyzed by Chi-square test and Fisher's test used Statistical Product and Servicer Solution (SPSS) version 17. The results showed that the patient's knowledge level was $22.6 \%$ classified as poor, $48 \%$ classified as moderate, and $29.4 \%$ classified as good. The use of self-medication is $26.3 \%$ irrational and $73.7 \%$ rational. Based on the results of the study, it was found that the patient's level of knowledge was classified as moderate with a percentage of $48 \%$. While self-administered rationality is classified as rational with a percentage of $73.7 \%$.
\end{abstract}

Keywords: Self-medication, Pharmacy, Knowledge, Rationality of drug use 


\section{PENDAHULUAN}

Pengobatan sendiri (self medication) merupakan upaya yang paling banyak dilakukan masyarakat untuk mengatasi keluhan atau gejala penyakit sebelum mereka memutuskan mencari pertolongan ke pusat pelayanan kesehatan/petugas kesehatan (Depkes RI, 2008). Mengobati diri sendiri atau yang lebih dikenal dengan swamedikasi berarti mengobati segala keluhan dengan obat-obatan yang dapat dibeli bebas di apotek atau toko obat dengan inisiatif atau kesadaran diri sendiri tanpa nasehat dokter (Muharni, 2015). Berdasarkan hasil Riset Kesehatan Dasar (Riskesdas) 2013, 35,2\% rumah tangga menyimpan obat untuk swamedikasi (Kemenkes RI, 2015).

Swamedikasi biasanya dilakukan untuk mengatasi keluhan-keluhan dan penyakit ringan yang banyak dialami masyarakat, seperti demam, nyeri, pusing, batuk, influenza, sakit maag, kecacingan, diare, penyakit kulit dan lain-lain (Depkes RI, 2006). Salah satu penyebab tingginya tingkat swamedikasi adalah perkembangan teknologi informasi via internet. Alasan lain adalah karena semakin mahalnya biaya pengobatan ke dokter, tidak cukupnya waktu yang dimiliki untuk berobat, atau kurangnya akses ke fasilitas-fasilitas kesehatan (Gupta, et al., 2011; Hermawati, 2012).

Swamedikasi harus dilakukan sesuai dengan penyakit yang dialami, pelaksanaannya sedapat mungkin harus memenuhi kriteria penggunaan obat yang rasional. Kriteria obat rasional antara lain ketepatan pemilihan obat, ketepatan dosis obat, tidak adanya efek samping, tidak adanya kontraindikasi, tidak adanya interaksi obat, dan tidak adanya polifarmasi (Muharni, 2015).

Sampai saat ini di tengah masyarakat seringkali dijumpai berbagai masalah dalam penggunaan obat. Diantaranya ialah kurangnya pemahaman tentang penggunaan obat tepat dan rasional, penggunaan obat bebas secara berlebihan, serta kurangnya pemahaman tentang cara menyimpan dan membuang obat dengan benar. Sedangkan tenaga kesehatan masih dirasakan kurang memberikan informasi yang memadai tentang penggunaan obat (Kemenkes RI, 2015). Oleh karena itu, sebagai pelaku selfmedication harus mampu mengetahui jenis obat yang diperlukan, kegunaan dari tiap obat, menggunakan obat dengan benar (cara, aturan pakai, lama pemakaian), mengetahui efek samping obat yang digunakan dan siapa yang tidak boleh menggunakan obat tersebut (Depkes RI, 
2008). Secara umum keterampilan PIO apoteker dalam swamedikasi sakit kepala dan flu ini bertujuan untuk memberian informasi kepada pasien bagaimana cara swamedikasi obat atas kesadaran diri sendiri tanpa nasehat dokter.

\section{METODOLOGI}

\section{A. Jenis Penelitian}

Penelitian ini merupakan penelitian deskriptif yang menggambarkan fenomena yang diteliti yang terjadi di dalam suatu populasi tertentu, menggunakan desain pendekatan crosssectional (Swarjana,2012).

\section{B. Lokasi dan Waktu Penelitian}

\section{Lokasi penelitian}

Penelitian ini dilaksanakan di tiga apotek di Kota Purwokerto. Apotek dipilih berdasarkan lokasi yang strategis dan pemilik apotek yang bersedia memberikan izin untuk dilakukannya penelitian.

\section{Waktu penelitian}

Penelitian ini dilaksanakan pada bulan September 2018 dari jam $09.00 \mathrm{~s} / \mathrm{d} 21.00 \mathrm{WIB}$ di tiga apotek di Kota Purwokerto.

\section{Populasi dan Sampel}

\section{Populasi}

Pada penelitian ini populasi yang digunakan adalah semua pasien swamedikasi berusia $18-60$ tahun dari tiga apotek di Kota Purwokerto.

\section{Sampel}

Sampel dalam penelitian ini adalah pasien swamedikasi berusia $18-60$ tahun dari tiga apotek di Kota Purwekerto yang memenuhi kriteria inklusi. Pengambilan sampel dilakukan dengan metode consecutive sampling sampai jumlah sampel yang dibutuhkan terpenuhi serta berdasarkan waktu pengumpulan data yang tersedia (Swarjana, 2012).

Kriteria inklusi :

a. pasien yang datang ke apotek untuk melakukan swamedikasi.

b. pasien berumur $18-60$ tahun.

c. pasien yang dapat berkomunikasi dengan baik.

Kriteria eksklusi :

a. pasien yang tidak bersedia bekerja sama dalam penelitian ini.

\section{Pengambilan Data}

Sumber data dalam penelitian ini yaitu data primer yang diperoleh secara langsung dari responden melalui pengisian kuesioner. Kuesioner dalam 
penelitian ini terdiri dari 4 bagian, yaitu bagian pendahuluan untuk mengetahui: apakah pasien pernah menggunakan obat swamedikasi, bagian pengetahuan swamedikasi bertujuan untuk mengetahui tingkat pengetahuan pasien tentang swamedikasi, bagian rasionalitas swamedikasi bertujuan untuk mengetahui rasionalitas obat swamedikasi yang digunakan responden dan bagian data demografi responden yang bertujuan untuk mengetahui karakteristik responden. Kuesioner yang digunakan sebelumnya dilakukan uji validitas dan reliabilitas.

\section{E. Analisis Data}

Tingkat pengetahuan dibagi menjadi 3 kategori yaitu tingkat pengetahuan baik (skor <60\%), sedang (skor 60\%-80\%) dan buruk (skor $>80 \%$ ). Sedangkan rasionalitas dikategorikan menjadi 2 yaitu rasional jika memenuhi enam kriteria ketepatan pengobatan sendiri dan tidak rasional jika tidak memenuhi enam kriteria ketepatan pengobatan sendiri. Dilakukan pengolahan data menggunakan SPSS. Analisis data dilakukan melalui 2 tahap, yaitu analisis univariat, digunakan untuk mendapatkan gambaran distribusi frekuensi karakteristik demografi dan variabel lain. Analisis bivariat, digunakan untuk mengetahui hubungan sosiodemografi dengan tingkat pengetahuan tentang swamedikasi dan rasionalitas swamedikasi menggunakan uji chi-square dan fisher.

\section{HASIL DAN PEMBAHASAN}

\section{A. Karakteristik Responden}

Sebanyak 300 responden yang berasal dari tiga apotek di Kota Purwokerto yang terlibat dalam penelitian ini, 100 responden berasal dari apotek A, 113 responden berasal dari apotek B, dan 87 responden berasal dari apotek C. Berdasarkan hasil penelitian ini, responden didominasi oleh perempuan (64\%) dengan golongan umur 29-39 tahun $(31,4 \%)$ dan mayoritas pendidikan terakhir adalah SMA $(55,4 \%)$ dengan kategori pekerjaan yang paling banyak adalah ibu rumah tangga (34,6\%). Data lengkap dapat dilihat pada Tabel 1 
Tabel 1. Karakteristik Sosiodemografi Seluruh Responden

\begin{tabular}{|l|c|c|}
\hline Variabel & Jumlah (N) (300) & Persentase (\%) \\
\hline Umur & 90 & 30,9 \\
a.18-28 tahun & 100 & 31,4 \\
b.29-39 tahun & 65 & 20,3 \\
c.40-49 tahun & 45 & 17,4 \\
d.50-60 tahun & & \\
\hline Jenis kelamin & 100 & 36 \\
a. Laki-laki & 200 & 64 \\
b. Perempuan & & \\
\hline Pendidikan & 3 & 0,9 \\
Terakhir & 32 & 10,6 \\
a. Tidak tamat SD & 65 & 17,4 \\
b. SD & 150 & 55,4 \\
c. SMP & 50 & 15,7 \\
d. SMA & & \\
e. Perguruan Tinggi & & 6 \\
\hline Pekerjaan & 21 & 10,9 \\
a. Tidak/belum & 28 & 1,1 \\
bekerja & 4 & 10 \\
b. Karyawan & 35 & 0,3 \\
c. Guru & 1 & 71,7 \\
d. Mahasiswa & 211 & \\
e. Tenaga & & $\mathbf{1 0 0}$ \\
Kesehatan & $\mathbf{3 0 0}$ & \\
f. Lainnya & & \\
\hline Total & & \\
\hline
\end{tabular}

\section{B. Sumber Informasi dan Tempat}

\section{Memperoleh Obat Swamedikasi}

\section{Sumber informasi memperoleh obat} swamedikasi

Berdasarkan hasil penelitian ini dapat diketahui bahwa mayoritas responden melakukan swamedikasi berdasarkan pengalaman pribadi/keluarga $(38,9 \%)$. Data lengkap dapat dilihat pada Gambar.1. Hasil penelitian ini sejalan dengan penelitian terdahulu yang menunjukkan bahwa mayoritas responden melakukan pengobatan sendiri karena pengalaman penggunaan obat pribadi/keluarga (Harahap, 2015). 


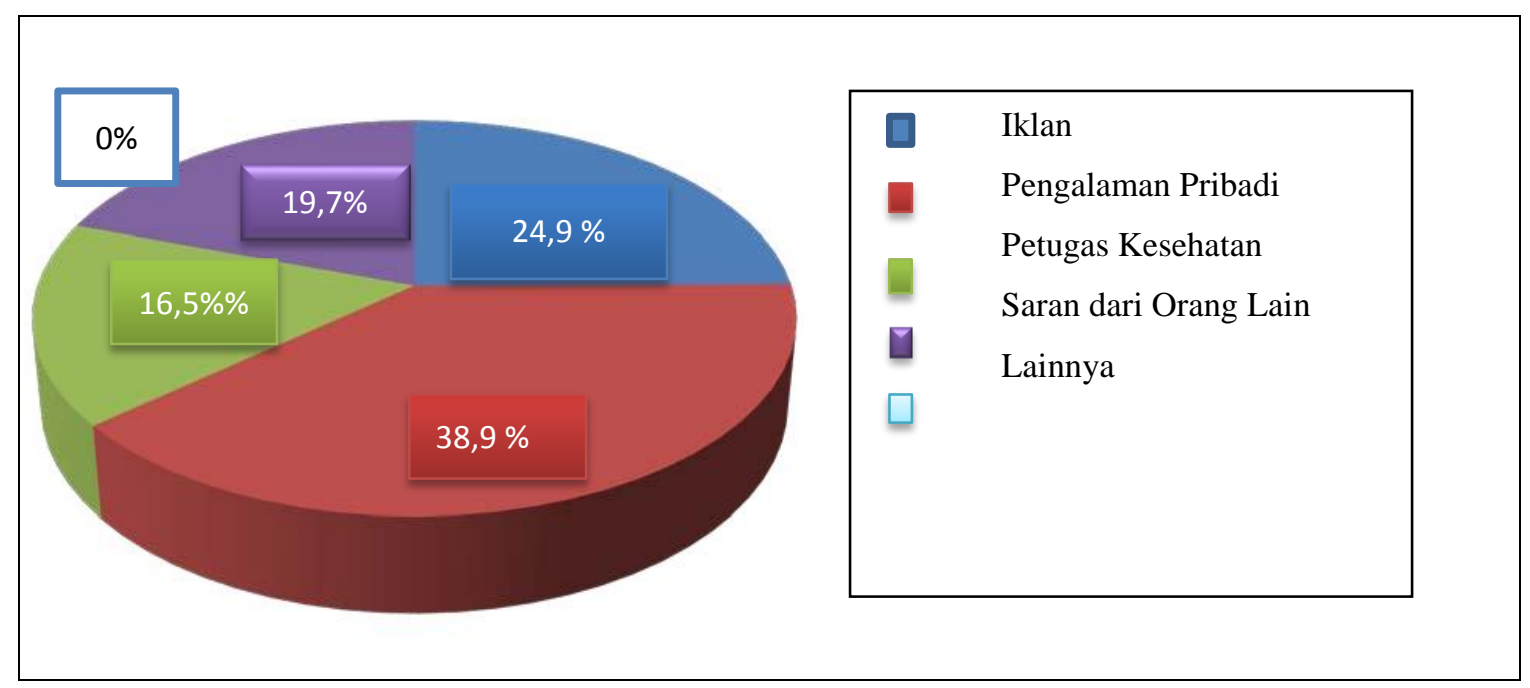

Gambar 1 Sumber Informasi Memperoleh Obat Swamedikasi

2. Tempat memperoleh obat dari warung $(27,4 \%)$, supermarket

\section{swamedikasi}

Berdasarkan hasil penelitian ini dapat diketahui bahwa persentase terbanyak responden memperoleh obat tanpa resep dokter yang digunakan yaitu dari apotek $(68,9 \%)$ dikarenakan banyak responden beranggapan bahwa di apotek adalah tempat yang tepat untuk memperoleh obat yang terjamin kualitasnya dan banyak jenis obat yang dapat diperoleh. Selain apotek responden juga memperoleh obat yang digunakan
$(3,7 \%)$. Data lengkap dapat dilihat pada Gambar 4.2. Hasil penelitian ini sejalan dengan penelitian terdahulu yang menunjukkan bahwa mayoritas responden memperoleh obat tanpa resep dari apotek (Mellina, 2016). Hal ini dikarenakan bahwa obat-obat yang dijual di apotek lebih dapat dipercaya mutu dan keasliannya, sehingga apotek lebih dipilih sebagai tempat pembelian obat (Hermawati, 2012).

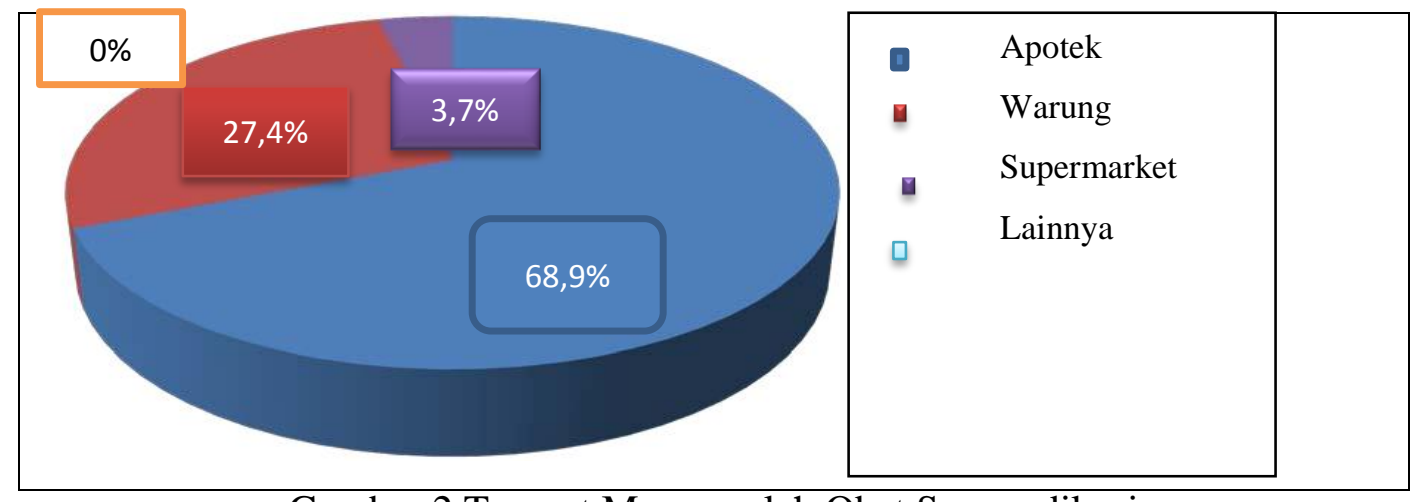

Gambar 2 Tempat Memperoleh Obat Swamedikasi 


\section{Tingkat Pengetahuan Responden tentang Swamedikasi}

Berdasarkan hasil penilaian yang dilakukan dapat diketahui bahwa mayoritas tingkat pengetahuan responden di tiga apotek Kota Purwokerto tergolong sedang (48\%). Data lengkap dapat dilihat pada Tabel 2.

Tabel 2. Frekuensi Tingkat Pengetahuan Seluruh Responden

\begin{tabular}{|lll|}
\hline Kriteria & Frekuensi & Persentase (\%) \\
\hline Buruk & 69 & 22,6 \\
\hline Sedang & 138 & 48 \\
\hline Baik & 93 & 29,4 \\
\hline Total & 350 & 100 \\
\hline
\end{tabular}

Hasil penelitian ini sejalan dengan penelitian di Kecamatan Cimanggis (Depok) dan Kota Panyabungan yang menunjukkan bahwa mayoritas tingkat pengetahuan pasien swamedikasi tergolong sedang (Hermawati, 2012; Harahap, 2015). Namun berbeda dengan penelitian yang dilakukan di Kecamatan Medan Marelan yang menunjukkan mayoritas tingkat pengetahuan pasien swamedikasi tergolong buruk (Mellina, 2016). Data lengkap dapat dilihat pada Tabel 3.

Tabel 3. Distribusi Pengetahuan Responden tentang Swamedikasi

\begin{tabular}{|c|l|c|c|c|}
\hline \multirow{2}{*}{ No } & \multicolumn{1}{|c|}{ Soal } & \multicolumn{3}{|c|}{ Jawaban } \\
\cline { 3 - 5 } & & Benar (\%) & Salah (\%) & Tidak tahu (\%) \\
\hline 1. & Definisi Swamedikasi & $144(52,6)$ & $40(11,4)$ & $116(36)$ \\
\hline 2. & Logo obat-obatan & $152(52)$ & $39(14)$ & $109(34)$ \\
\hline 3. & $\begin{array}{l}\text { Perbedaan obat batuk } \\
\text { kering dan batuk } \\
\text { berdahak }\end{array}$ & $257(87,7)$ & $15(4,3)$ & $28(8)$ \\
\hline 4. & Aturan pakai obat & $270(77,1)$ & $41(14,6)$ & $19(8,3)$ \\
\hline 5. & $\begin{array}{l}\text { Defenisi aturan pakai } \\
\text { 3x sehari }\end{array}$ & $146(47,4)$ & $112(37,7)$ & $42(14,9)$ \\
\hline 6. & Pengertian indikasi obat & $207(64,9)$ & $11(6)$ & $82(29,1)$ \\
\hline 7. & $\begin{array}{l}\text { Pengertian } \\
\text { kontraindikasi obat }\end{array}$ & $169(56,9)$ & $35(10)$ & $96(33,1)$ \\
\hline 8. & $\begin{array}{l}\text { Pengertian efek } \\
\text { samping obat }\end{array}$ & $243(78)$ & $43(15,1)$ & $14(6,9)$ \\
\hline 9. & $\begin{array}{l}\text { Pengertian interaksi } \\
\text { obat }\end{array}$ & $107(36,3)$ & $55(18,6)$ & $138(45,1)$ \\
\hline 10. & $\begin{array}{l}\text { Aturan penyimpanan } \\
\text { obat }\end{array}$ & $252(83,4)$ & $35(12,9)$ & $13(3,7)$ \\
\hline
\end{tabular}


Berdasarkan jawaban dari seluruh responden dapat disimpulkan bahwa sebagian besar pertanyaan yang diberikan tidak dapat dijawab dengan benar oleh responden. Mayoritas responden menjawab dengan baik mengenai perbedaan antara obat batuk kering dengan obat batuk berdahak $(87,7 \%)$. Tetapi responden paling sedikit menjawab pertanyaan dengan baik mengenai interaksi obat $(36,3 \%)$. Hal ini dapat disebabkan karena kurangnya pemahaman tentang obat-obatan (Kemenkes RI, 2015).
D. Rasionalitas Penggunaan Obat dalam Swamedikasi

Berdasarkan hasil penilaian mengenai rasionalitas penggunaan obat, dapat disimpulkan bahwa mayoritas responden yang melakukan swamedikasi di tiga apotek Kota Purwokerto menggunakan obat secara rasional $(73,7 \%)$. Data lengkap dapat dilihat pada Tabel 4.

Tabel 4. Frekuensi Rasionalitas Penggunaan Obat Swamedikasi

\begin{tabular}{|lll|}
\hline Kategori & Frekuensi & Persentase (\%) \\
\hline Tidak rasional & 82 & 26,3 \\
\hline Rasional & 218 & 73,7 \\
\hline Total & 350 & 100 \\
\hline
\end{tabular}

Berdasarkan hasil penilaian pada setiap kriteria rasionalitas, tidak rasionalnya penggunaan obat paling banyak disebabkan oleh adanya efek samping obat $(18,9 \%)$. Data lengkap dapat dilihat pada Tabel 5

Tabel 5. Distribusi Status Penilaian Untuk Setiap Kriteria Rasionalitas

\begin{tabular}{|l|c|c|c|}
\hline \multicolumn{1}{|c|}{ Kriteria } & Status & Jumlah & Persentase (\%) \\
\hline Ketepatan pemilihan & Tidak tepat & 5 & 1,4 \\
obat & Tepat & 295 & 98,6 \\
\hline Ketepatan dosis obat & Tidak tepat & 20 & 5,7 \\
& Tepat & 280 & 94,3 \\
\hline Efek samping obat & Ada & 46 & 18,9 \\
& Tidak ada & 254 & 81,1 \\
\hline Kontraindikasi & Ada & 6 & 1,7 \\
\hline
\end{tabular}




\begin{tabular}{|l|c|c|c|}
\hline & Tidak ada & 294 & 98,3 \\
\hline Interaksi obat & Ada & 0 & 0 \\
& Tidak ada & 300 & 100 \\
\hline Polifarmasi & Ada & 6 & 1,7 \\
& Tidak ada & 294 & 98,3 \\
\hline
\end{tabular}

Hasil penelitian ini sejalan dengan penelitian yang dilakukan di Kecamatan Cimanggis (Depok) yang menunjukkan bahwa tidak rasionalnya penggunaan obat paling banyak disebabkan oleh adanya efek samping yang mengganggu pada penggunaan obat responden meskipun pada dosis normal. Efek samping obat memang diakui dirasakan oleh beberapa responden pada penggunaan obat-obat Over The Counter (OTC). Meskipun begitu, banyak pula dari mereka yang tidak menyadari, apakah reaksi yang dirasakan merupakan suatu efek samping atau bukan. Hal tersebut diasumsikan sebagai salah satu bentuk ketidakwaspadaan reponden terhadap efek samping dari obat yang digunakannya (Hermawati, 2012). Seorang pelaku swamedikasi seharusnya mengetahui efek samping obat yang digunakan sehingga dapat memperkirakan apakah suatu keluhan yang timbul kemudian merupakan suatu penyakit baru atau efek sampingobat. Dengan begitu, mereka dapat segera menanggulanginya jika ternyata efek tersebut merugikan diri mereka (Depker RI, 2008).

Namun hal ini tidak sejalan dengan penelitian yang dilakukan di Kota Panyabungan dan Kecamatan Medan Marelan yang menunjukkan bahwa tidak rasionalnya penggunaan obat paling banyak disebabkan oleh ketidaktepatan penggunaan dosis obat (Harahap, 2015; Mellina, 2016).

Ketidaktepatan pemilihan obat dalam penelitian ini yaitu ketidaksesuaian indikasi obat yang dipilih dengan keluhan pasien seperti antibiotik untuk keluhan penyakit pegal atau capek, demam kurang dari 3 hari, dan lambung, menggunakan obat flu untuk keluhan sakit kepala. Perlu diingat bahwa obat juga memiliki efek yang tidak diinginkan. Bentuk kesalahan misalnya seseorang sakit kepala, tapi yang diminum obat flu. Memang kebanyakan obat flu mengandung obat sakit kepala, tapi 
obat flu juga mengandung obat-obat lainnya. Ibarat membunuh satu penjahat yang sebenarnya hanya perlu satu peluru, tetapi dilakukan dengan granat, penjahat itu mati, tetapi kerusakan yang ditimbulkan juga lebih banyak (Widodo, 2004).

Ketidaktepatan dosis obat dalam penelitian ini meliputi dosis sekali pakai dan cara penggunaan obat. Hal ini dapat disebabkan karena responden hanya fokus pada pengalaman pribadi atau keluarga dan mengesampingkan informasi yang ada tentang pengobatan. Kasus lain responden menggunakan antibiotik tidak sampai habis, hal ini dapat menimbulkan masalah obat tidak manjur, kepekaan berlebihan setelah digunakan secara lokal, resistensi (bakteri menjadi kebal dan tidak dapat dibunuh lagi dengan obat tersebut), terjadi infeksi lain (sekunder) (Widodo, 2004).

Pemilihan obat bermerek yang digunakan bersamaan juga harus memperhatikan kandungannya karena obat bermerek dapat mengandung lebih dari satu macam obat. Pada sebagian obat, pabrik obat diperbolehkan membuat obat dengan merek masingmasing walaupun sebenarnya macam kandungan obat atau zat aktifnya sama atau hampir sama (Widodo, 2004). Hal tersebut dapat mengakibatkan polifarmasi jika tidak diperhatikan seperti penggunaan Panadol dengan Sanmol yang memiliki kandungan serupa yaitu Parasetamol 500 mg.

\section{KESIMPULAN}

1. Tingkat pengetahuan pasien tentang swamedikasi di tiga apotek Kecamatan Medan Sunggal, mayoritasnya adalah tingkat pengetahuan tergolong sedang $(48 \%)$.

2. Rasionalitas swamedikasi pasien di tiga apotek Kecamatan Medan Sunggal yaitu tergolong rasional $(73,7 \%)$.

\section{SARAN}

1. Dinas Kesehatan Kota Purwokerto perlu memberikan promosi mengenai cara memilih dan menggunakan obat dengan benar dan tepat.

2. Diharapkan kepada mahasiswa farmasi ataupun tenaga kesehatan lainnya agar lebih aktif dalam melakukan penyuluhan kepada masyarakat tentang pengetahuan swamedikasi. 
3. Diharapkan kepada masyarakat agar lebih mencari informasi tentang obat-obatan dari sumber yang dapat dipercaya khususnya petugas kesehatan.

4. Pada penelitian selanjutnya diharapkan agar peneliti dapat menambahkan faktor-faktor yang dapat mempengaruhi tingkat pengetahuan dan rasionalitas swamedikasi seperti sikap dan penghasilan responden.

\section{DAFTAR PUSTAKA}

Anief. (1997). Apa yang Perlu Diketahui tentang Obat. Yogyakarta: Gajah Mada

University Press.

Badan Pusat Statistik. (2015). Medan Sunggal dalam Angka 2015. Medan: Badan Pusat Statistik Kota Medan.

Bogadenta, A. (2012). Manajemen Pengelolaan Apotek. Yogyakarta: DMedika.

Hal. 18-19.

Depkes RI. (2006). Pedoman Penggunaan Obat Bebas dan Terbatas. Jakarta:

Departemen Kesehatan Republik Indonesia. Hal. 8, 22-37, 31-35, 38-41, 47-50.

Depkes RI. (2008). Materi Pelatihan Peningkatan Pengetahuan dan Keterampilan Memilih Obat Bagi Tenaga Kesehatan. Jakarta: Departemen Kesehatan Republik Indonesia. Hal. 0, 6-8, 9, 10.

Garofalo, L., Gabriella D. G., dan Italo, F. A. (2015). Self Medication Practice among Parents in Italy. Biomed Research International. Hal. 1-8.
Gupta, P., Bobhate, P., dan Shrivastava, S. (2011). Determinants of Self Medication Practices in an Urban Slum Community. Asian Journal Pharmaceutical and Clinical Research. 4(3): 54-57.

Harahap, N. A. (2015). Tingkat Pengetahuan dan Rasionalitas Swamedikasi di Tiga Apotek Kota Panyabungan. Skripsi. Medan: Fakultas Farmasi Universitas Sumatera Utara.

Hermawati, D. (2012). Pengaruh Edukasi Terhadap Tingkat Pengetahuan dan Rasionalitas Penggunaan Obat Swamedikasi Pengunjung di Dua Apotek Kecamatan Cimanggis, Depok. Skripsi. Fakultas Matematika dan Ilmu Pengetahuan Alam Program Studi Farmasi UI.

Kemenkes RI. (2015). Pemahaman Masyarakat Akan Penggunaan Obat Masih

Rendah. Jakarta: Pusat Komunikasi Publik.

Keputusan Menteri Kesehatan RI No. 347/Menkes/SK/VII/1990 tentang Obat

Wajib Apotek. Jakarta: Departemen Kesehatan RI.

Keputusan Menteri Kesehatan 1176/MENKES/SK/X/1999 tentang Daftar Obat Wajib Apotek No.3. Jakarta: Departemen Kesehatan RI.

Khomsan, A. (2000). Teknik Pengukuran Pengetahuan Gizi. Bogor: Departemen

Gizi dan Sumber daya Keluarga, Fakultas Pertanian IPB. Hal. 11. Universitas Sumatera Utara

Kristina, S., Prabandari, Y., dan Sudjaswadi, R. (2008). Perilaku Pengobatan Sendiri Yang Rasional Pada Masyarakat. Majalah Farmasi Indonesia. Yogyakarta: Fakultas Farmasi. Universitas Gajah Mada. 19(1): 32-40. 
Lapau, B. (2012). Metode Penelitian Kesehatan: Metode Ilmiah Penulisan Skripsi, Tesis, dan Disertasi. Edisi Revisi. Jakarta: Pustaka Obor Indonesia. Hal. 42.

Lwanga, S. K., dan Lameshow, S. (1991). Sampel Size Determination in Health

Studies. Geneva: World Health Organization. Hal. 25.

Mellina, I. (2016). Tingkat Pengetahuan Pasien dan Rasionalitas Swamedikasi di Empat Apotek Kecamatan Medan Marelan. Skripsi. Medan: Fakultas Farmasi Universitas Sumatera Utara.

Menkes RI. (2016). Peraturan Menteri Kesehatan No. 73 Tahun 2016 tentang

Standar Pelayanan Kefarmasian di Apotek. Jakarta: Departemen Kesehatan RI.

Mubarak, W. I., dkk. (2007). Promosi Kesehatan: Sebuah Pengantar Proses Belajar Mengajar dalam Pendidikan. Yogyakarta: Graha Ilmu. Hal. 83-84.

Muharni, S., Fina, A., dan Maysharah, M. (2015). Gambaran Tenaga Kefarmasian dalam Memberikan Informasi Kepada Pelaku Swamedikasi di ApotekApotek Kecamatan Tampan, Pekanbaru. Jurnal Sains Farmasi \& Klinis. 2(1): 47-53.

Notoatmodjo, S. (2003). Ilmu Kesehatan Masyarakat: Prinsip-Prinsip Dasar. Jakarta: Rineka Cipta. Hal. 127-130.

Peraturan Menteri Kesehatan 919/Menkes/Per/X/1993 tentang Kriteria Obat yang

Dapat Diserahkan Tanpa Resep. Jakarta: Departemen Kesehatan RI.

Peraturan Menteri Kesehatan 924/MENKES/PER/X/1993 tentang Daftar Obat Wajib Apotek No.2. Jakarta: Departemen Kesehatan RI.
Peraturan Menteri Kesehatan 925/MENKES/PER/X/1993 tentang Daftar Perubahan Golongan Obat No.1. Jakarta: Departemen Kesehatan RI.

Peraturan Menteri Kesehatan No. 9 Tahun 2017 tentang Apotek. Jakarta: Departemen Kesehatan RI. PP RI No 51. (2009). Tentang Pekerjaan Kefarmasian. Jakarta. Hal. 1-3.

Simamora, B. (2008). Panduan Riset Perilaku Konsumen. Jakarta: Gramedia Pustaka Utama. Hal. 59.

Supardi, S., dan Susyanty, A. L. (2010). Penggunaan Obat Tradisional Dalam Upaya Pengobatan Sendiri Di Indonesia (Analisis Data Susenas Tahun Universitas Sumatera Utara 2007). Buletin Penelitian Kesehatan. Jakarta: Pusat Penelitian dan Pengembangan Sistem dan Kebijakan Kesehatan. 38(2): 80-89.

Swarjana, I. K. (2012). Metodologi Penelitian Kesehatan. Yogyakarta: CV Andi

Offset. Hal. 51, 102.

Talawo, D. P. (2014). Pengaruh Leaflet Terhadap Tingkat Pengetahuan Penggunaan Obat Swamedikasi Di Desa Tingkohubu Timur Kecamatan Suwawa. Jurnal Penelitian Farmasi. Gorontalo: Fakultas Farmasi Universitas Negeri Gorontalo. Hal. 1-12.

Trihendradi, C. (2011). Langkah Mudah Melakukan Analisis Statistik Menggunakan SPSS 19. Yogyakarta: Penerbit Andi. Hal. 145-147, 215217.

Zeenot, S. (2013). Pengelolaan dan Penggunaan Obat Wajib Apotek. Jogjakarta: D-Medika. Hal. 109112, 139 dan 143. 